On the other hand, water diuresis is inefficient and the kidney has difficulty in getting rid of a big water load such as that of a litre of water.

Thus, in determining the amount of fluid that we should give to these patients we have to bear in mind that the kidney needs water in considerable quantity in order to excrete its solutes with the minimum of energy expenditure. About 31 ./day is probably the optimum quantity. On the other hand, excess of water should be avoided. Fortunately the thirst mechanism guides the patient effectively in most cases, and so long as he is provided with fluid in sufficient quantity he is usually quite capable of judging for himself the amount that he should drink.

\title{
REFERENCES
}

Black, D. A. K. (1952). Brit. F. Nutrit. 6, 428.

McCance, R. A. (1945-6). F. Physiol. 104, 196.

Platt, R. (195I). Lancet, 260, 1239.

Rapoport, S., Brodsky, W. A., West, C. D. \& Mackler, B. (1949). Amer. F. Physiol. 156, 433.

Roscoe, M. H. (1952). Brit. F. Nutrit. 6, 432.

\section{Salt and Hypertension}

\section{By D. A. K. BLACK, Department of Medicine, Royal Infirmary, Manchester}

Both the substantives of my title stand in some need of definition. 'Salt' is used not as a chemical expression, but as the ordinary description of sodium chloride; there is fairly general agreement that sodium is more important than chloride in sustaining blood pressure, and this is not without practical importance, as some of the 'salt substitutes' on the market, though free from chloride, contain sodium citrate. 'Hypertension' denotes a physical finding, that of raised blood pressure, and not a disease state; as clinical knowledge advances, we are able to distinguish patients in whom renal disease, suprarenal disease, or disease of the central nervous system accounts for the elevated blood pressure. Most patients with raised blood pressure have, however, no demonstrable primary disease to account for their hypertension; they are said to suffer from 'essential hypertension', and it is with this limited group of hypertensive patients that I propose to deal. Sustained hypertension can in itself cause damage to the kidneys, heart, and brain; most of the patients from whom we have derived data have a normal excretory function, but in one this was reduced to about a quarter of normal.

The practice of salt restriction in hypertension antedates considerably any acceptable rationale for the procedure. Widal and his school seem to have introduced it about 50 years ago, but its use in the English-speaking world dates from the enthusiastic advocacy of Allen in America in the nineteen-twenties. Hypertension is a syndrome in which the actual blood-pressure level is very variable, and there may be a considerable fall in blood pressure when the patient is removed from active life, especially if he is rested in bed. It is also a syndrome which is quite compatible with long survival after its initial discovery. Each of these considerations makes it difficult to assess the value of any proposed therapy, and until a few years ago the general opinion seemed 
to be that salt restriction of the type then practised could not be shown to influence the course or severity of the syndrome. From this statement, one must except those patients with hypertension of some standing and severity who are threatened with cardiac failure, associated with cardiac asthma or peripheral oedema; in them, salt restriction may alleviate the fluid retention found at this stage of the syndrome.

Interest has been revived by the work of Kempner (1944) on the rice and fruit-juice diet for hypertension. He claimed improvement in the blood-pressure level, and also in heart size, retinopathy, and electro-cardiographic findings. Attempts to confirm these findings in America met with varying success. In this country, a Medical Research Council trial (Anonymous, 1950) was made in a number of centres, and it was found that in about $70 \%$ of patients with hypertension a considerable fall of blood pressure could be produced. A diet of rice and fruit juices is, however, very monotonous, and though an obsessional patient may be induced to take it for long periods at the instance of an enthusiastic physician like Kempner, the usual hypertensive patient in this country soon gives it up. The rice diet represents severe restriction of sodium and chloride, with an intake of about $5 \mathrm{~m}$-equiv./day. This is not without risk, especially if mercurial diuretics are also used, and Schroeder (1949) has reported a number of patients who became seriously depleted of salt, with low plasma volume and poor renal function in consequence.

The rice diet is probably impracticable for long-continued use. On the other hand, the usual 'salt-free' diet supplies about $3 \mathrm{~g}$ salt daily, and salt restriction at this high level is probably without effect on the blood pressure. By using specially prepared salt-free bread, a diet with less than I $g$ salt daily can be provided without undue monotony, and this may possibly find some place in the treatment of hypertension. At present, interest has shifted to the methonium group of drugs, which are probably capable of producing a larger chronic fall in blood pressure than can be accomplished by salt restriction.

Although the rice diet is scarcely a practical therapeutic measure, the trials carried out in this centre gave us the chance of comparing the response to it in normal and hypertensive subjects. In neither group was there any unequivocal change in plasmasodium levels; and although we have not studied this extensively, there does not seem to be any fall in plasma volume. We were specially interested in comparing the renal conservation of sodium in normal and hypertensive subjects, in view of the claims made by Perera \& Blood (1946) that hypertensive patients conserved body fluid more effectively than normal controls, when subjected to salt restriction. Their studies covered only a $24 \mathrm{~h}$ period of salt restriction, and they based their conclusion mainly on change in body-weight and urine output. In only two subjects was the clearance of sodium and chloride measured, and it is said to have been reduced in the hypertensive patients; this would imply enhanced conservation of sodium.

Our own studies were made on two normal and five hypertensive subjects; one of the normals had three separate experiences of the rice-fruit diet. Specimens of urine were collected every $24 \mathrm{~h}$ on the rice diet, and the sodium output on successive days was determined. The sodium excretion in both groups fell to levels of 5-10 m-equiv./ day, and the groups did not differ significantly in the level reached. Increase in urine 
volume, which Perera \& Blood found in their normal group, but not in the hypertensive group, occurred in our series in two experiments with normal and three with hypertensive subjects. Our main conclusions, however, are based on the rate of decline of sodium output in the urine over the first 5 days of salt restriction. If $Q_{t}$ is the $24 \mathrm{~h}$ sodium output on day $t$, and $Q_{0}$ the initial sodium output, then

$$
Q_{t}=Q_{0} \times \epsilon^{-\alpha t}
$$

$\alpha$ being a constant which expresses the rate of disappearance of sodium from the urine. The value of $\alpha$ is given by the slope of the regression line of the quantity $-\log _{\varepsilon} Q_{t} / Q_{0}$ on time. We have calculated this regression for our normal and hypertensive people and the numerical values are as follows:

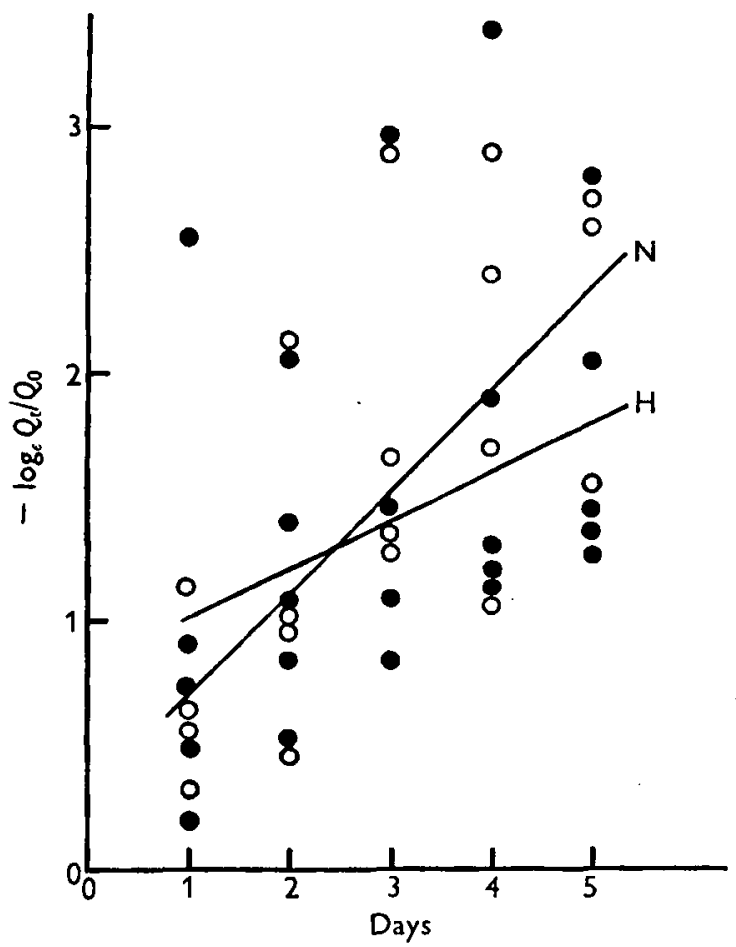

Fig. I. Plot of the quantity $-\log _{\epsilon} Q_{t} / Q_{0}$ against time. $O$, data from normal people; , data from hypertensive patients.

Experiments with normal people

$$
\begin{array}{ll}
\hat{Y}=0 \cdot 19+0 \cdot 44 X, \\
\text { where } & Y=-\log _{\varepsilon} Q_{t} / Q_{0} \text { and } X=t .
\end{array}
$$

The standard error, $S_{b}$, of the regressive coefficient $b=0.44$ is 0.098 , so that the limiting values for $P=0.05$ are $0.24-0.64$. (See also Fig. I.)

Experiments with hypertensive patients

$$
\begin{aligned}
& \hat{Y}=0.8 \mathrm{I}+0.22 X, \\
& S_{b}=0 . I \mathrm{I} .
\end{aligned}
$$

Limits for $P=0.05$ are $0-0.45$. (See also Fig. I.) 
These results would seem to indicate that hypertensive subjects do not conserve sodium more effectively than normal subjects, and it is possible that they do so less effectively. Our results are thus in conflict with the conclusions of Perera $\&$ Blood (1946).

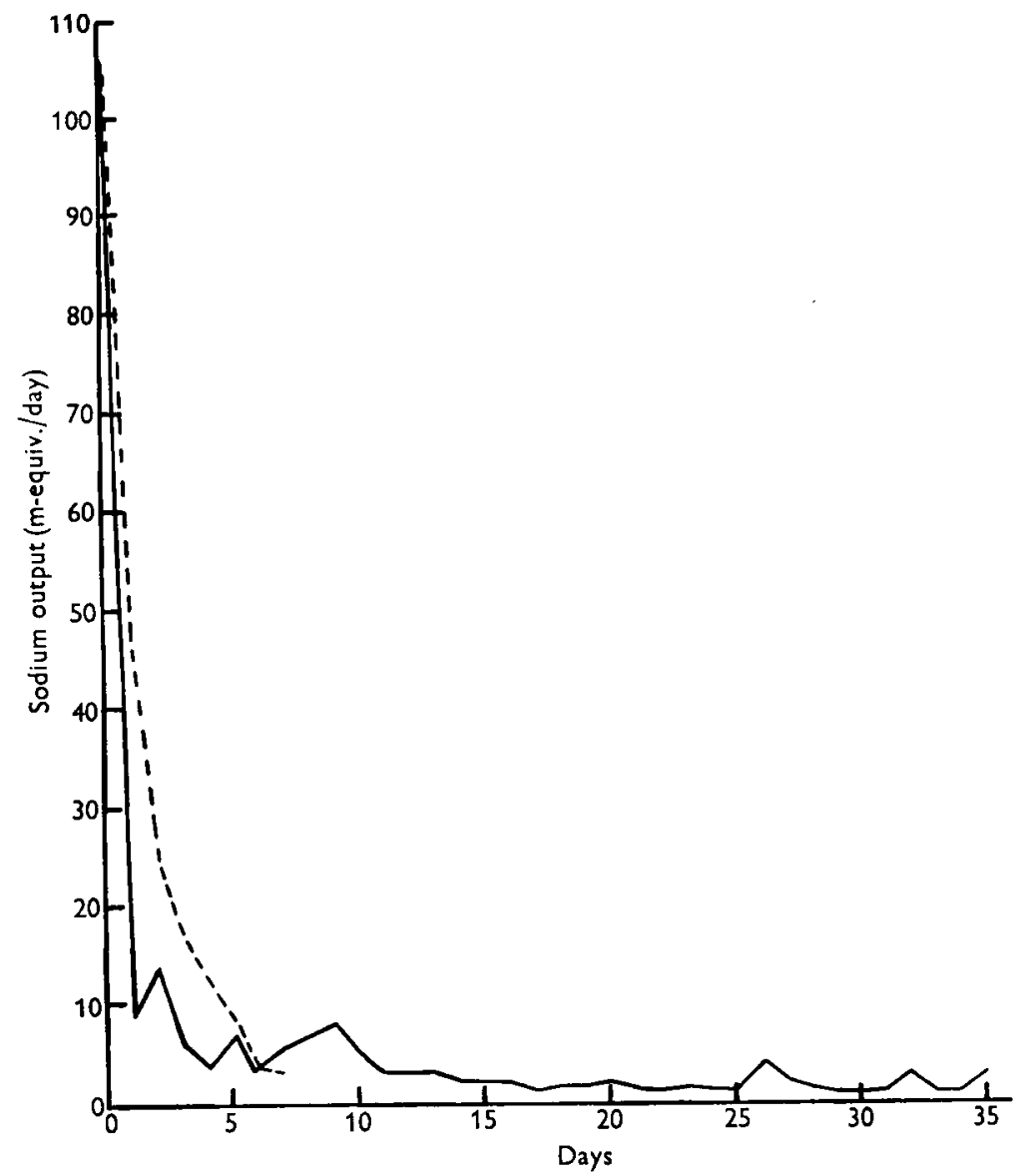

Fig. 2. Comparison of the decline in daily sodium output on the rice diet in a normal (-- -) and an exceptional hypertensive subject (-).

We should point out, however, that one of our hypertensive patients showed a remarkable power of salt conservation, as shown in Fig. 2, but even including her in the series, as we have done, does not bring the general hypertensive performance up to normal levels. The one patient with depressed renal function did not fail to conserve salt.

The method of computation adopted compares each day's excretion with the initial day's output, and so might be biased if there were an undue collection error on the Ist day of salt depletion. As a check on this, we have also taken the ratio of sodium output on the later days $\left(Q_{n}\right)$ to the sodium output on each preceding day $\left(Q_{n-1}\right)$. The average $Q_{n}: Q_{n-1}$ for normal people is 0.64 , and for hypertensive patients 0.82 , which is in accord with the more detailed results presented. 
It has been claimed that overproduction of salt-retaining adrenal steroids is concerned in the production of essential hypertension, and Perera \& Blood (1946) relate the failure of hypertensives to lose salt and water on a salt-free diet to this. In experimental hypertension (Floyer, 195I) the effect of adrenalectomy in bringing down the blood pressure can be prevented by supplying salt. It would seem from this and from previous work that the ability to conserve salt is essential to maintainance of blood pressure; but our present results do not support the view that the 'cause' of essential hypertension is an overproduction of the hormones which mediate salt conservation.

\section{SUMMARY}

I. The practice of salt restriction in the treatment of essential hypertension is discussed.

2. Five hypertensive patients did not conserve sodium more efficiently than normal subjects, when placed on a low-salt diet.

3. This study does not support the view that an excess of salt-retaining steroids is present in essential hypertension.

I am indebted to Professor R. Platt for the results on sodium output on the rice diet.

\section{REFERENCES}

Anonymous (1950). Lancet, 259, 509.

Floyer, M. A. (1951). Clin. Sci. 10, 405.

Kempner, W. (r944). Med. $\mathcal{~}$. N. Carolina, 5, 125.

Perera, G. A. \& Blood, D. W. (1946). Amer. F. Med. I, 602.

Schroeder, H. A. (1949). F. Amer. med. Ass. r41, I 17.

\section{Diet and Chronic Renal Disease}

\section{By M. Honora Roscoe, Department of Medicine, University of Manchester}

Chronic renal disease includes a number of conditions that must be diagnosed before treatment can be carried out, but here only two will be considered; chronic type 2 nephritis and the chronic renal failure which develops following acute type I nephritis, chronic pyelonephritis or malignant hypertension.

\section{Chronic type 2 nephritis}

This is the only variety of chronic renal disease in which recovery occurs, so that treatment is particularly worth while. But although dietetic treatment would clearly appear to be indicated and may improve the symptoms, we can seldom be certain that is has had any curative effect.

The condition is characterized by marked albuminuria, which results in lowering of the plasma proteins, especially albumin, and in protracted cases in normochromic anaemia (Roscoe, 1950). There is also oedema, often of a very severe degree and, with this, sodium retention.

Treatment consists of a high protein intake to improve the plasma-protein concen- 